\title{
Rationality of two fuzzy negotiation solutions by Knowledge Engineering to n-person cooperative games
}

\author{
Erick González ${ }^{1}$, Rafael A. Espín ${ }^{1}$, Gustavo Mazcorro ${ }^{2}$, Salvador Muñoz $^{1}$ \\ ${ }^{1}$ Higher Technical Institute "José Antonio Echeverría", Havana, Cuba \\ ${ }^{2}$ Instituto Politécnico Nacional-UPIICSA, Cd. de Mexico, Mexico
}

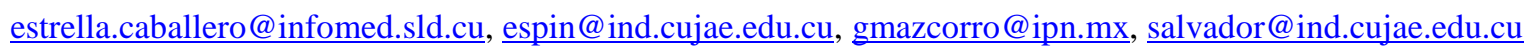

\begin{abstract}
The aim of this paper is to prove the rationality of two new fuzzy solutions to cooperative n-person games. They are the Fuzzy Negotiation Solution by Knowledge Engineering and Compensatory Negotiation Solution by Knowledge Engineering, which are based on bargaining over statements coming from experts. The proof of rationality consists in demonstrating that the elements of crisp solutions equivalent to these fuzzy solutions satisfy Imputation, Efficiency, Symmetry, Dummy Axiom and others.
\end{abstract}

Keywords: Fuzzy logic, Solution to cooperative n-person games, Rationality.

\section{Introduction}

The Shapley Value is a classic solution concept for coalitional n-person games with transferable utility. It is the unique function that satisfies the Shapley's axiom set: Efficiency or Pareto Optimality, Equal Treatment or Symmetry, Null Player or Dummy, and Additivity ([14]). The first three axioms are considered of rationality in accordance with normative Decision Theory ([7]) and Game Theory, [12]. However, the fourth axiom is polemical in Game Theory because of its lack of rationality, see [12]. The Shapley Value is a well accepted solution because of its existence and uniqueness; yet other classic solutions, the Core for instance, frequently do not satisfy these properties

([12]).

The Fuzzy Negotiation Solution by Knowledge Engineering (FNSKE) and the Compensatory Negotiation Solution by Knowledge Engineering (CNSKE) are recent, advantageous solutions in the theory of cooperative n-person games, [4, 8]. They are based on propositions coming from experiences in bargaining and negotiation among $n$ parts. The propositions are provided by experts on negotiation in a non-mathematical way and represented in natural language. The solution is a set of vectors, one for every possible coalition among the players; each vector has the gains for the $n$ players in the coalition, and in addition, the truth value of a membership function, e.g. [15], representing the likelihood of reaching a deal in the respective coalition.
The aim of this paper is to prove that crisp solutions equivalent to the FNSKE and CNSKE satisfy the axioms of imputation, three of the Shapley's axiom set, i.e., Efficiency, Symmetry and Dummy; non-negativeness, proportionality and equality. On the other hand, one counterexample is examined to show that the fuzzy solutions do not satisfy the polemical Additivity Axiom. This is a manner to support the rationality of the FNSKE and CNSKE in agreement with the Normative Approach to Decision Making, [7].

\section{Basic Concepts of Cooperative N-Person Games and the Shapley Value}

A cooperative n-person game is a pair $(\mathrm{N}, \mathrm{v})$, where $\mathrm{N}$ $=\{1,2, \ldots, n\}$ is a non-empty, finite set of players. A coalition is an element of the power set of $\mathrm{N}$, denoted by $2^{\mathrm{N}}$. $\mathrm{v}$ is the characteristic function of the game, which maps $2^{\mathrm{N}}$ into the set of real numbers $\mathfrak{R}$, satisfying the following properties:

$$
\begin{aligned}
\text { i. } & \mathrm{v}(\varnothing)=0 \\
\text { ii. } & \mathrm{v}(\mathrm{S} \cup \mathrm{T}) \geq \mathrm{v}(\mathrm{S})+\mathrm{v}(\mathrm{T}), \text { where } \mathrm{S} \text { and } \mathrm{T} \text { are disjoints } \\
& \text { coalitions of } 2^{\mathrm{N}} .
\end{aligned}
$$

The value $\mathrm{v}(\mathrm{S})$ is the worth of $\mathrm{S}$ (its members act together, as a single unit). Property ii is called superadditivity, it implies that the worth of a coalition is greater than or equal to the worth of any subcoalition (a subset of the coalition). Additive and subadditive characteristic functions also exist, but they are not considered in this paper. An imputation (see [12]) is a payoff allocation $\mathbf{x}=\left(\mathrm{x}_{1}\right.$, $\left.\mathrm{x}_{2}, \ldots, \mathrm{x}_{\mathrm{n}}\right)$ that satisfies:

i. $\quad \sum_{\mathrm{i}=1}^{\mathrm{n}} \mathrm{x}_{\mathrm{i}}=\mathrm{v}(\mathrm{N})$, then $\mathrm{x}$ is said to be group rational or efficient.

ii. $\quad \mathrm{x}_{\mathrm{i}} \geq \mathrm{v}(\{\mathrm{i}\})$, and $\mathrm{x}$ is said to be individually rational.

An imputation is a division of worth among the players, such that the sum of their individual values is exactly the worth of the coalition of all players (or grand coalition). Also, each player obtains a gain that is at least equal to their individual value. The Shapley Value is one of the most important solution concepts in cooperative games. The Shapley Value of a game $(\mathrm{N}, \mathrm{v})$ is the unique n-tuple, $\phi(\mathrm{v})=$ 
$\left(\phi_{1}(\mathrm{v}), \phi_{2}(\mathrm{v}), \ldots, \phi_{\mathrm{n}}(\mathrm{v})\right)$ that satisfies the four axiom set of rationality, [14], that is:

1. Efficiency. $\sum_{\mathrm{i} \in \mathrm{N}} \phi_{\mathrm{i}}(\mathrm{v})=\mathrm{v}(\mathrm{N})$.

2. Symmetry. For all bijections $\pi: \mathrm{N} \rightarrow \mathrm{N}$ and $\mathrm{i} \in \mathrm{N}$, $\phi_{\pi(\mathrm{i})}(\mathrm{v})=\phi_{\mathrm{i}}\left(\mathrm{v}^{\circ} \pi\right)$.

3. Dummy Axiom. If $i$ is such that $v(S)=v(S \cup\{i\})$ for any coalition $S$ not containing $i$, then $\phi_{i}(v)=0$.

4. Additivity. If $\mathrm{u}$ and $\mathrm{v}$ are characteristic functions, then $\phi(\mathrm{u}+\mathrm{v})=\phi(\mathrm{u})+\phi(\mathrm{v})$.

Efficiency signifies that the set of all players profits exactly the worth of the grand coalition. The interpretation of Symmetry is that the Shapley Value solution is independent of any order assigned to the players. The meaning of the Dummy Axiom is that a player that does not contribute to the worth of any coalition obtains a null value solution. Additivity indicates that if a game is defined as the sum of two different games, then the solution of the resulting game is equal to the sum of the solutions of the two games, played separately or at different times. The last is, however, controversial because Additivity is just a fairly convincing simplification of the intrinsic complexity meant by playing two different games, [3].

If $\mathrm{v}(\mathrm{S})$ is interpreted as a worth of $\mathrm{S}$, if it is formed, one may argue that $(\mathrm{N}, \mathrm{v}+\mathrm{w})$ does not represent "properly", the aggregate of the games $(\mathrm{N}, \mathrm{v})$ and $(\mathrm{N}, \mathrm{w})$, because $\mathrm{S}$ may be "more likely" to form one of these games and less like in the other, see [10]. Additivity Axiom seems only reasonable if there are no complementary relations between the assets of the two enterprises, [10].

One method, based on a different principle, is employed by an "enterprise" consisting of husband and wife, who want to decide on a divorce settlement. Wife takes back every item that she brought out the marriage, husband does the same and the rest is divided equally among the couple. This method of sharing in proportion to the investments is not additive ([10]).

A proper theorem guaranties the existence and uniqueness of the Shapley Vector in regard to the axioms 1-4, [14].

\section{A Fuzzy Approach to Cooperative N-Person Games}

A recent kind of fuzzy solution to cooperative n-person games ([4]) is a model of bargaining based upon expert knowledge, summarized in four propositions, extracted from the literature on negotiation, expressed in natural language; to know [1, 6, 11]:

1. A negotiation part has bargaining capacity if and only if the following conditions hold:

- The contribution of its institution to the settlement (agreement, or business) in discussion is important.

- The part can find feasible alternatives and some advantages if no settlement is reached, or its contribution is essential.

2. Any increase in contribution to the business by one of the parts, or an increase in benefits due to its cor- responding alternatives, increases its bargaining capacity.

3. The benefit obtained by each part is equal to the amount that it could obtain without the contribution of other parts, plus a portion of the additional benefit derived from the settlement. This increment obtained by each part is approximately proportional to its bargaining capacity.

4. A settlement is possible if and only if all the parts are important to the business and the corresponding benefit to every part is important to each of them.

This is an example of application of Knowledge Engineering outside the concept of rationality. "The process of working with an expert to map what he or she knows into a form suitable for an expert system to use has come to be known as knowledge engineering " ([2]). Nevertheless, it will be proved in what follows that this model also satisfies classic concepts of rationality.

Definition 1 The Good Deal Index (GDI) of negotiator $i$, from the point of view of negotiator $j$, in a given bargaining-set, is the benefit that $i$ could obtain if the collective benefits estimated by $\mathrm{j}$ prevailed, and the whole set of negotiators including $\mathrm{j}$ had a similar performance in defense of their interests during the bargaining process.

In this fuzzy model the institutions are represented by the players in $\mathrm{N}$, the bargaining sets are represented by coalitions belonging to $2^{\mathrm{N}}$, and the characteristic function represents the benefits obtained in the bargaining-sets. A formula of the GDI is developed in [4, 8]:

$$
\mathbf{X}(i, C)=\left\{\begin{array}{l}
v(\{i\})+\frac{r(i, C)}{\sum_{j \in C} r(j, C)} \\
\cdot\left[v(C)-\sum_{j \in C} v(\{j\})\right] \text { if } i \in C, \\
0 \quad \text { if } i \notin C
\end{array}\right.
$$

Where $r(i, C) \in[0,1]$ is the truth value of the fuzzy predicate "player $i$ has bargaining capacity in the bargaining set $\mathrm{C}$ ". The fuzzy logic system used in this model is the Probabilistic Fuzzy Logic. Operators' formulas of this system are:

- $u(p \wedge q)=u(p) u(q)$. Conjunction.

- $\quad u(p \vee q)=u(p)+u(q)-u(p) u(q)$. Disjunction.

- $\mathrm{u}(\neg \mathrm{p})=1-\mathrm{u}(\mathrm{p})$. Negation.

- $\quad \mathrm{i}(\mathrm{x}, \mathrm{y})=\mathrm{d}(\mathrm{n}(\mathrm{x}), \mathrm{y})$. Natural Implication.

The following equation is a consequence of Proposition 2:

$$
\mathrm{r}(\mathrm{i}, \mathrm{C})=\mathrm{p}(\mathrm{i}, \mathrm{C}) \wedge\left(\mathrm{a}(\mathrm{i}, \mathrm{C}) \vee \mathrm{p}^{2}(\mathrm{i}, \mathrm{C})\right)(2)
$$

Predicates $\mathrm{p}(\mathrm{i}, \mathrm{C})$ and $\mathrm{a}(\mathrm{i}, \mathrm{C})$ correspond to the statements "player $\mathrm{i}$ is important to coalition $\mathrm{C}$ ", and "player $\mathrm{i}$ has feasible and advantageous alternatives to reach an agreement within $\mathrm{C}^{\prime \prime} . \mathrm{p}(\mathrm{i}, \mathrm{C})$ is squared in order to model 
the linguistic modifier related to the statement "very", [16].

The following expression is used as a strict fuzzy order:

$$
\begin{aligned}
& \mathrm{O}(\mathrm{C}, \mathrm{D})=\mathrm{o}(\mathrm{v}(\mathrm{C}), \mathrm{v}(\mathrm{D}))= \\
& \frac{0.5}{\lambda}\left[\frac{\mathrm{v}(\mathrm{C})-\mathrm{v}(\mathrm{D})}{\max _{\mathrm{E}, \mathrm{F} \in 2^{\mathrm{N}}}|\mathrm{v}(\mathrm{E})-\mathrm{v}(\mathrm{F})|}\right]+0.5(3) \\
& , \lambda>1
\end{aligned}
$$

$\mathrm{p}(\mathrm{i}, \mathrm{C})=\mathrm{O}(\mathrm{C}, \mathrm{C} \backslash\{\mathrm{i}\})$ and $\mathrm{q}(\mathrm{i}, \mathrm{C})=\mathrm{o}(\mathbf{X}(\mathrm{i}, \mathrm{C}), \mathrm{v}(\{\mathrm{i}\}))$ correspond to the affirmations "coalition $\mathrm{C}$ obtains more benefits than coalition $\mathrm{C} \backslash\{\mathrm{i}\}$ ", and "player i obtains more benefits in coalition $C$ than in coalition $\{i\} "$ ", respectively. Thus, these affirmations correspond to the statements "the contribution of $\mathrm{i}$ is important for coalition C", and "coalition $\mathrm{C}$ is important for player $\mathrm{i}$ ".

The predicate:

$$
\begin{aligned}
& \mathrm{S}(\mathrm{i}, \mathrm{C}, \mathrm{D})= \\
& \frac{0.5}{\lambda}\left[\frac{\mathbf{X}(\mathrm{i}, \mathrm{C})-\mathbf{X}(\mathrm{i}, \mathrm{D})}{\max _{\mathrm{E}, \mathrm{F} \in 2^{\mathrm{N}}}|\mathrm{v}(\mathrm{E})-\mathrm{v}(\mathrm{F})|}\right]+0.5^{(4)}
\end{aligned}
$$

corresponds to the statement "i obtains more benefits in coalition $\mathrm{C}$ than in coalition $\mathrm{D}$ ".

The formula of the predicate corresponding to the statement of Proposition 4: "it is possible to reach an agreement within coalition $\mathrm{C}^{\prime \prime}$, is the following:

$$
f(C)=\left(\wedge_{j \in C}(p(j, C) \wedge q(j, C))\right.
$$

And the statement: "there are advantageous and possible alternatives for player $\mathrm{i}$ to reach an agreement within coalition $\mathrm{C}^{\prime}$, is modeled by the expression:

$\mathrm{a}(\mathrm{i} ; \mathrm{C})=\vee_{\mathrm{B} \neq \mathrm{C},\{\mathrm{i}\} \subset \mathrm{B}}(\mathrm{s}(\mathrm{i} ; \mathrm{B} ; \mathrm{C}) \wedge \mathrm{f}(\mathrm{B}))$

The value of $\lambda$ has been obtained experimentally, so that $\lambda=1.0494$. The GDI is then calculated by the recurrent formula:

$$
\mathbf{X}(\mathrm{i}, \mathrm{C})=\mathrm{g}(\mathbf{X}(\mathrm{i}, \mathrm{C}))
$$

in which $\mathrm{g}$ is the operator that transforms nxm matrices into nxm matrices. It generates the GDI of all players considering the possible coalitions of the game.

The solution of the game is finally obtained by the expression:

$$
\begin{aligned}
& \mathrm{S}=\left\{\left(\mathbf{X}\left(1, \mathrm{C}_{\mathrm{j}}\right), \mathbf{X}\left(2, \mathrm{C}_{\mathrm{j}}\right), \cdots, \mathbf{X}\left(\mathrm{n}, \mathrm{C}_{\mathrm{j}}\right) ; \mathrm{f}\left(\mathrm{C}_{\mathrm{j}}\right)\right):\right. \\
& \left.: \mathrm{j}=1,2, \cdots, \operatorname{card}\left(2^{\mathrm{N}}\right)\right\}
\end{aligned}
$$

Expression (7) yields a set of vectors; each has n elements that are a division of worth among the players in the coalition, and the truth value of $\mathrm{f}(\mathrm{C})$ according to (5).
The Counterpart Convenience Index 1 (CCI1) of the player $\mathrm{i}$, in the coalition $\mathrm{C}$ of game $\mathrm{v}$ is denoted by $\mathrm{D}_{\mathrm{v}}(\mathrm{i}, \mathrm{C})$, it is equal to:

$$
D_{v}(i, C)=q_{v}(i, C) \wedge f_{v}(C)
$$

This index allows to rank coalitions by order of convenience for each player $i$.

Definition 2 ([4]) Let $v$ be an n-person game and $\beta$ a partition of $N$. A sub-game $v_{\beta}$ of $v$ and $\beta$ is defined to be a game whose players are all the sets in $\beta$ (coalitions). A subgame satisfies: $v_{\beta}\left(\left\{F_{1}, F_{2}, \ldots, F_{n}\right\}\right)=v\left(\cup_{i=1}{ }^{n} F_{i}\right)$.

An index, called Counterpart Convenience Index 2 (CCI2) is defined by:

$$
\begin{aligned}
& \mathrm{d}_{\mathrm{v}}(i, C)=\mathrm{D}_{\mathrm{v}}(i, C) \wedge \\
& \wedge\left\{\mathrm{q}_{\mathrm{v}}^{2}(i, C) \vee\left\{\underset{\substack{\hat{C} \subset \beta \\
S \neq\{C\}}}{\vee \vee} \mathrm{D}_{\mathrm{v} \beta}(C, S)\right\}\right\}
\end{aligned}
$$

This index models the statement: "The bargaining set $\mathrm{C}$ is convenient for 4 player $i$ whenever the following conditions are satisfied:

- it is possible to obtain and advantageous agreement in this set.

- if the agreement is not very advantageous for $\mathrm{i}$ then, no matter what structure of coalition had been presented, a convenience bargaining set $\mathrm{S}$ for the coalition $C$ (as a player of $v_{\beta}$ ) exists"

Let $\mathrm{v}_{\beta}$ be a sub-game created after the negotiation with a structure of coalition $\beta$. The CCI 2 indicates the convenience of renegotiating, where every $C \in \beta$ negotiates like a single player. The joint of the solution set in formula (7), the CCI1 given by formula (8), and the CCI2 given by formula (9), is the Fuzzy Negotiation Solution by Knowledge Engineering (FNSKE). For any cooperative n-person game, a unique GDI exists ([4]).

Compensatory Negotiation Solution by Knowledge Engineering (CNSKE) is a new solution that improves the FNSKE. It consists in the substitution of logical system; the Geometric mean based compensatory logic (GMBCL) by the Probabilistic Fuzzy Logic.

Geometric mean based compensatory logic is a new advantageous fuzzy logic system that satisfies the most important axioms of Decision Theory. Its operators of conjunction and disjunction are continuous and satisfy the idempotency ([5]). Some of the main operators of this system are:

- $\quad c:[0,1]^{\mathrm{n}} \rightarrow[0,1]$, such that

$$
\mathrm{c}\left(\mathrm{x}_{1}, \mathrm{x}_{2}, \cdots, \mathrm{x}_{\mathrm{n}}\right)=\sqrt[n]{\prod_{\mathrm{i}=1}^{\mathrm{n}} \mathrm{x}_{\mathrm{i}}} \text {. Conjunction. }
$$

- $\quad \mathrm{d}:[0,1]^{\mathrm{n}} \rightarrow[0,1]$, such

$$
\mathrm{d}\left(\mathrm{x}_{1}, \mathrm{x}_{2}, \cdots, \mathrm{x}_{\mathrm{n}}\right)=1-\sqrt[\mathrm{n}]{\prod_{\mathrm{i}=1}^{\mathrm{n}}\left(1-\mathrm{x}_{\mathrm{i}}\right)} \text {. Disjunction. }
$$


- $\mathrm{n}:[0,1] \rightarrow[0,1]$, such that $\mathrm{n}(\mathrm{x})=1-\mathrm{x}$. Negation.

- $\quad \mathrm{i}:[0,1]^{2} \rightarrow[0,1]$, such that $\mathrm{i}(\mathrm{x}, \mathrm{y})=\mathrm{d}(\mathrm{n}(\mathrm{x}), \mathrm{y})$. Natural Implication. Or, $\mathrm{i}(\mathrm{x}, \mathrm{y})=\mathrm{d}(\mathrm{n}(\mathrm{x}), \mathrm{c}(\mathrm{x}, \mathrm{y}))$. Implication of Zadeh.

An inconvenience of this logical system is that, contrary to the probabilistic logic, if the number of players increases, then no necessarily decreases the bargaining capacity, this is because of the compensatory tendency of the system. For this reason, it is necessary to complement the previous propositions with a new one that takes into account the quantity of players in each coalition. Keeping this in mind, a change to the fourth proposition is as follows:

4. A settlement is possible if and only if the following conditions are satisfied:

- All the parts are important to the business and the corresponding benefit to every part is important to each of them.

- The number of parts associated to the settlement is not large.

The change to the fourth proposition implies a change in (5). The new formula of the "likelihood to reach an agreement in the coalition $\mathrm{C}$ " is the following:

$f(C)=\left(\wedge_{j \in C}(p(j, C) \wedge q(j, C))\right) \wedge J(\operatorname{card}(C))$

Where $J(\operatorname{card}(C))$ is the membership function of the proposition: "the quantity of players in the coalition $\mathrm{C}$ is not large". Function $\mathrm{J}$ depends on the cardinal number of $\mathrm{C}, \operatorname{card}(\mathrm{C})$.

The function $\mathbf{J}$ was modeled using the negation of the sigmoidal membership function having the following formula: $\mathrm{J}(\operatorname{card}(\mathrm{B}))=1-\frac{1}{1+\mathrm{e}^{-\alpha(\operatorname{card}(\mathrm{B})-\gamma)}}$,

$\alpha=\frac{\ln (0.9)-\ln (0.1)}{\gamma-\beta} \quad, \gamma, \beta \in \mathbf{N}$.

Evidently $J(\beta)=0.9$ and $J(\gamma)=0.5$. The function $\operatorname{sig}(x)=\frac{1}{1+e^{-\alpha(x-\gamma)}}$ models the proposition "the quantity of players in the coalition $\mathrm{C}$ is large". The other formulas remain as stated.

Compensatory Model 2 ([8]), with parameters $\beta=1$ and $\gamma=4$, minimizes the relative error between GDI of the FNSKE and the GDI of the following formula:

$X(i, C)=\left\{\begin{array}{l}v(\{i\})+\frac{r^{2}(i, C)}{\sum_{j \in C} r^{2}(j, C)} . \\ \cdot\left[v(C)-\sum_{j \in C} v(\{j\})\right] \text { if } i \in C, \\ 0 \quad \text { if } i \notin C\end{array}\right.$

This means that the players of each coalition have a much bargaining capacity, according to the linguistic modifiers or hedges used empirically in fuzzy logic. The relative error between both GDI is less than $5 \%$ with a probability of 0.95 , according to the statistical comparison of both models. This solution exists and it is unique.

These fuzzy solutions are different of others appeared in the literature of games. For example, the fuzzy cooperative games, see [9], are obtained applying the extension principle to the classic solutions to games.

Solutions based on the surplus, like in [13], distribute it equally, but in FNSKE and CNSKE the weights used to distribute the surplus are a consequence of the bargaining capacity of each player, which is a fairer and a more realistic criterion.

Definition 3 Let $(\mathrm{N}, \mathrm{v})$ be a cooperative n-person game. A "crisp" solution equivalent to the FNSKE and the CNSKE for this game is: $\mathrm{x} \in \max _{\mathrm{f}(\mathrm{C})} \min _{\text {card(C) }}$ Sc, where $\mathrm{Sc}=\{\mathrm{y} \in \mathrm{S}$ such that its corresponding coalition $\mathrm{C}$ satisfies: $\mathrm{v}(\mathrm{C})=\mathrm{v}(\mathrm{N})\}$. $\mathrm{S}$ is the solution set defined by $(7)$, and the $\mathrm{f}(\mathrm{C})$ of $\mathrm{x}$ is maximal among those corresponding to the elements of Sc.

That is to say, this is the set of vector solutions of $S$, satisfying they have the same gain of the gain in grand coalition, their 'likelihood to reach an agreement' is a maximum and their number of players is a minimum. It is a rational choice for a deterministic solution to the game. The crisp solution is comparable with the classic solutions for cooperative n-person games. This solution is not empty, because the vector solution corresponding to the grand coalition are contained in $\mathrm{S}_{\mathrm{c}}$, see [4].

Example 1 An actual example of bargaining is the following, taken from [11]:

Three companies: Scandinavian Cement Company, Cement Corporation and Thor Cement Company monopolize the Scandinavian market and are trying to meet an agreement to share profits, thus avoiding harmful competition. For this, they hire an independent consultant who calculates the minimal amount each company can obtain in terms of million of dollars. This is therefore reflected in the n-person game stated below, in which the companies are identified by the order in which they appear above:

$\mathrm{v}(\{1\})=30, \mathrm{v}(\{2\})=22, \mathrm{v}(\{3\})=5, \mathrm{v}(\{1,2\})=59$, $\mathrm{v}(\{1,3\})=45, \mathrm{v}(\{2,3\})=39, \mathrm{v}(\{1,2,3\})=77$.

The results are summarized in the tables below:

\begin{tabular}{|l|l|l|l|l|}
\hline & $\{1\}$ & $\{2\}$ & $\{3\}$ & $\{1,2\}$ \\
\hline 1 & 30 & 0 & 0 & 33.8017 \\
\hline 2 & 0 & 22 & 0 & 25.1983 \\
\hline 3 & 0 & 0 & 5 & 0 \\
\hline
\end{tabular}

Table 1. GDI for each cement company in million of dollars for the FNS(K1)

)
\begin{tabular}{|l|c|l|l|}
\hline & $\{1,3\}$ & $\{2,3\}$ & \multicolumn{1}{|c|}{$1,2,3$} \\
\hline 1 & 36.3970 & 0 & 37.9314 \\
\hline 2 & 0 & 29.1821 & 28.9974 \\
\hline 3 & 8.6030 & 9.8179 & 10.0713 \\
\hline
\end{tabular}

Table 2. GDI for each cement company in million of dollars for the FNSKE 


\begin{tabular}{|r|c|c|r|r|}
\hline & $\{1\}$ & $\{2\}$ & $\{3\}$ & $\{1,2\}$ \\
\hline 1 & 30 & 0 & 0 & 33.7391 \\
\hline 2 & 0 & 22 & 0 & 25.2609 \\
\hline 3 & 0 & 0 & 5 & 0 \\
\hline
\end{tabular}

Table 3. GDI for each cement company in million of dollars for the CNSKE

\begin{tabular}{|l|l|l|l|}
\hline & $\{1,3\}$ & $\{2,3\}$ & $\{1,2,3\}$ \\
\hline 1 & 36.0709 & 0 & 37.6637 \\
\hline 2 & 0 & 28.8843 & 28.9178 \\
\hline 3 & 8.9291 & 10.1157 & 10.4185 \\
\hline
\end{tabular}

Table 4. GDI for each cement company in million of dollars for the CNSKE

\begin{tabular}{|l|l|l|l|}
\hline$\{1,2\}$ & $\{1,3\}$ & $\{2,3\}$ & $\{1,2,3\}$ \\
\hline 0.1411 & 0.1302 & 0.1293 & 0.0533 \\
\hline
\end{tabular}

Table 5. 'Likelihood to reach an agreement in the coalition' for the FNSKE

\begin{tabular}{|l|l|l|c|}
\hline$\{1,2\}$ & $\{1,3\}$ & $\{2,3\}$ & $\{1,2,3\}$ \\
\hline 0.7055 & 0.6985 & 0.6979 & 0.6437 \\
\hline
\end{tabular}

Table 6. 'Likelihood to reach an agreement in the coalition' for the CNSKE

According to definition (3) the crisp solution equivalent to the FNSKE is $(37.9314,28.9974,10.0713)$, see the ultimate column in table (2); and the crisp solution equivalent to the CNSKE is $(37.6637,28.9178,10.4185)$, see the ultimate column in table (4). None of the coalitions satisfy $\mathrm{v}(\mathrm{N})=77$, except the grand coalition itself. The Shapley Value is $(35.5,28.5,13)$.

The main advantage of the CNSKE over FNSKE is that the composed predicates can be interpreted as cardinal utility function, and not exclusively as ordinal utility function. Hence, every value of the table (6) can be interpreted straightforwardly, but in table (5) the values make sense only by comparing each other.

This is because the foundations of the solutions, the CNSKE is based on a fuzzy system which satisfies axioms of Decision Theory, where the fuzzy membeship functions are considered cardinal utility functions, because the conjunction and disjunction operators are idempotent and satisfy the compensation axiom.

\section{The Rationality of the Fuzzy Negotiation Solutions by Knowledge Engineering}

Theorem 1 Every vector of the FNSKE and CNSKE is an imputation.

Proof The fuzzy solutions obtained by (7) contain vectors having as their elements the values of the GDI for all the players in every coalition. The GDI can be calculated by (1) or (11), hence, $\forall \mathrm{i} \in \mathrm{C}$, the formula to calculate the elements of the vector is:

$$
\mathbf{X}(i, C)=\left\{\begin{array}{l}
\mathrm{v}(\{i\})+\frac{r^{\mathrm{s}}(\mathrm{i}, \mathrm{C})}{\sum_{j \in C} \mathrm{r}^{\mathrm{s}}(j, C)} . \\
\cdot\left[\mathrm{v}(\mathrm{C})-\sum_{j \in \mathrm{C}} \mathrm{v}(\{j\})\right] \text { if } i \in C, \\
0 \quad \text { if } i \notin C
\end{array}\right.
$$

Where $s=1$ for the FNSKE, and $s=2$ for the CNSKE.

$\lambda>1$ implies that $\mathrm{O}(\mathrm{C}, \mathrm{D})>0$ in $(3) . \mathrm{O}(\mathrm{C}, \mathrm{D})$ is the function used to define $\mathrm{p}(\mathrm{i}, \mathrm{C})$ and $\mathrm{q}(\mathrm{i}, \mathrm{C})$, so, they are strictly positive, and by using (5) and the fuzzy operators, $\mathrm{r}^{\mathrm{s}}(\mathrm{i}, \mathrm{C})>0 \forall \mathrm{i} \in \mathrm{C}$.

$$
\text { Thus, } 0<\frac{\mathrm{r}^{\mathrm{s}}(\mathrm{i}, \mathrm{C})}{\sum_{\mathrm{j} \in \mathrm{C}} \mathrm{r}^{\mathrm{s}}(\mathrm{j}, \mathrm{C})} \leq 1 \text { and }
$$

$\mathrm{v}(\mathrm{C})-\sum_{\mathrm{j} \in \mathrm{C}} \mathrm{v}(\{\mathrm{j}\}) \geq 0$, because $\mathrm{v}$ is superadditive.

Expression (12) and the last results imply that $\mathbf{X}(\mathrm{i}, \mathrm{C}) \geq$ $\mathrm{v}(\{\mathrm{i}\}), \forall \mathrm{i} \in \mathrm{C}$. Hence, $\mathbf{X}(\mathrm{i}, \mathrm{C})$ is individually rational. Further, (12) implies that $\sum_{\mathrm{i} \in \mathrm{C}} \mathbf{X}(\mathrm{i}, \mathrm{C})=\mathrm{v}(\mathrm{C})$, because $\sum_{i \in C} \frac{r^{s}(i, C)}{\sum_{j \in C} r^{s}(j, C)}=1$, then $\mathbf{X}(i, C)$ is group rational. Also, if $\mathrm{i} \notin \mathrm{C}$, then $\mathbf{X}(\mathrm{i}, \mathrm{C})=0$, hence, $\sum_{\mathrm{i} \in \mathrm{N}} \mathbf{X}(\mathrm{i}, \mathrm{C})=\mathrm{v}(\mathrm{C})$.

Corollary 1 The crisp solution equivalent to the FNSKE and CNSKE is an imputation.

Proof It is a particular case of theorem 1. $\square$

The individual rationality is a consequence of the proposition 3 for the FNSKE and CNSKE in the precedent section. On the other hand, the method of Fisher and Ury for negotiating advices that negotiation should be efficient (group rational), see [6].

Theorem 2 Every vector of the FNSKE and CNSKE satisfies the Efficiency and Symmetry of Shapley's axiomatic.

Proof Efficiency (group rational axiom) has been proved in Theorem 1 above. Now, for exploring Symmetry, let us prove that if $\pi: \mathrm{N} \rightarrow \mathrm{N}$ is a bijection and $\mathrm{i} \in \mathrm{C}$, then the solutions satisfy symmetry, this means: $\mathbf{X}_{\mathrm{v}}(\pi(\mathrm{i}), \pi(\mathrm{C}))=\mathbf{X}_{\mathrm{v}^{\circ} \pi}(\mathrm{i}, \mathrm{C}) \forall \mathrm{C} \in 2^{\mathrm{N}}$, where $\mathbf{X}_{\mathrm{v}}$ and $\mathbf{X}_{\mathrm{v}^{\circ} \pi}$ are the GDI for $\mathrm{n}$-person games with characteristic functions $\mathrm{v}$ and $\mathrm{v}^{\circ} \pi$ respectively.

$$
\begin{aligned}
& \mathbf{X}_{\mathrm{v}}^{0}(\pi(\mathrm{i}), \pi(\mathrm{C}))= \\
& =\left\{\begin{array}{l}
\mathrm{v}(\{\pi(\mathrm{i})\})+\eta_{i, C} \cdot \\
\cdot\left[\mathrm{v}(\pi(\mathrm{C}))-\sum_{\pi(\mathrm{j}) \in \pi(\mathrm{C})} \mathrm{v}(\{\pi(\mathrm{j})\})\right] \\
0
\end{array}\right.
\end{aligned}
$$

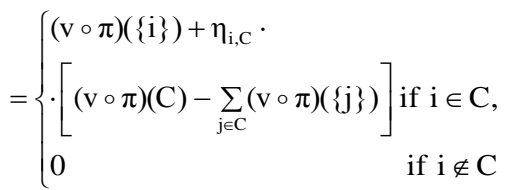

$=\quad \mathbf{X}_{\mathrm{v}^{\circ} \pi}^{0}(\mathrm{i}, \mathrm{C})$

Where $\eta_{\mathrm{i}, \mathrm{C}}$ are random values such that $\eta_{\mathrm{i}, \mathrm{C}} \in[0,1]$ and 
$\mathbf{X}_{\mathrm{v}}^{0}(\pi(\mathrm{i}), \pi(\mathrm{C}))$ is the initial value for the computation of the GDI by the recurrent equation: $\mathbf{X}=\mathrm{g}(\mathbf{X})$. Formula (3) implies that $\mathrm{O}_{\mathrm{v}^{\circ} \pi}(\mathrm{C}, \mathrm{D})=\mathrm{O}_{\mathrm{v}}(\pi(\mathrm{C}), \pi(\mathrm{D}))$. From definition of $\mathrm{p}_{\mathrm{v}}$ and $\mathrm{q}_{\mathrm{v}}$, the last property and the property $\mathbf{X}_{{ }_{v}}^{0}(\pi(\mathrm{i}), \pi(\mathrm{C}))=\mathbf{X}_{\mathrm{v}^{0} \pi}^{0}(\mathrm{i}, \mathrm{C})$, the following equalities can be obtained: $\mathrm{p}_{\mathrm{v}}(\pi(\mathrm{i}), \pi(\mathrm{C}))=\mathrm{p}_{\mathrm{v}}{ }(\mathrm{i}, \mathrm{C})$ and $\mathrm{q}_{\mathrm{v}}(\pi(\mathrm{i}), \pi(\mathrm{C}))=\mathrm{q}_{\mathrm{v}}{ }^{\circ}(\mathrm{i}, \mathrm{C})$. Thus, from formula (5) it follows the formula: $f_{v}(\pi(B))=f_{v^{\circ} \pi}(B)$. Therefore, $\mathrm{s}_{\mathrm{v}}(\pi(\mathrm{i}), \pi(\mathrm{C}), \pi(\mathrm{D}))=\mathrm{s}_{\mathrm{v}^{\circ} \pi}(\mathrm{i}, \mathrm{C}, \mathrm{D}), \mathrm{a}_{\mathrm{v}}(\pi(\mathrm{i}), \pi(\mathrm{C}))=\mathrm{a}_{\mathrm{v}^{\circ} \pi}(\mathrm{i}, \mathrm{C})$, $\mathrm{r}_{\mathrm{v}}(\pi(\mathrm{i}), \pi(\mathrm{C}))=\mathrm{r}_{\mathrm{v}^{\circ} \pi}(\mathrm{i}, \mathrm{C})$ and

$$
\frac{\mathrm{r}_{\mathrm{v}}^{\mathrm{s}}(\pi(\mathrm{i}), \pi(\mathrm{C}))}{\sum_{\pi(\mathrm{j}) \in \pi(\mathrm{r})}^{\mathrm{s}}(\pi(\mathrm{j}), \pi(\mathrm{C}))}=\frac{\mathrm{r}_{\mathrm{v} \pi}^{\mathrm{s}}(\mathrm{i}, \mathrm{C})}{\sum_{\mathrm{j} \in \mathrm{C}}^{\mathrm{r}} \mathrm{r}_{\mathrm{v} \pi}^{\mathrm{s}}(\mathrm{j}, \mathrm{C})}
$$

Hence, the GDI obtained from the first iteration of the recurrent equation $\mathbf{X}=\mathrm{g}(\mathbf{X})$ is:

$$
\begin{aligned}
& \mathbf{X}^{1}{ }_{\mathrm{v}}(\pi(\mathrm{i}), \pi(\mathrm{C}))= \\
& =\left\{\begin{array}{l}
\mathrm{v}(\{\pi(\mathrm{i})\})+\frac{r_{v}^{s}(\pi(i), \pi(C))}{\sum_{\pi(j) \in \pi(C)}^{s}(\pi(j), \pi(C))} . \\
\cdot\left[\mathrm{v}(\pi(\mathrm{C}))-\sum_{\pi(\mathrm{j}) \in \pi(\mathrm{C})} \mathrm{v}(\{\pi(\mathrm{j})\})\right] \\
\text { if } \pi(\mathrm{i}) \in \pi(\mathrm{C}), \\
0 \quad \text { if } \pi(\mathrm{i}) \notin \pi(\mathrm{C})
\end{array} .\right. \\
& =\left\{\begin{array}{l}
(\mathrm{v} \circ \pi)(\{\mathrm{i}\})+\frac{r_{v \circ \pi}^{s}(i, C)}{\sum_{j \in C} r_{v \circ \pi}^{s}(j, C)} . \\
\cdot\left[(\mathrm{v} \circ \pi)(C)-\sum_{j \in C}(\mathrm{v} \circ \pi)(\{\mathrm{j}\})\right] \text { if } i \in C, \\
0 \quad \text { if } i \notin C
\end{array}\right. \\
& =\mathbf{X}_{\mathrm{v}^{\circ} \pi}^{1}(\mathrm{i}, \mathrm{C}) \text {. }
\end{aligned}
$$

Following the same ideas, the m-th iteration in the calculation of the GDI satisfies: $\mathbf{X}_{\mathrm{v}}^{\mathrm{m}}(\pi(\mathrm{i}), \pi(\mathrm{C}))=$ $\mathbf{X}_{{ }^{\circ} \pi}{ }(i, C) \quad \forall m \in \mathbf{N}$, and, therefore, the limit of the last equality when $\mathrm{m} \rightarrow \infty$ is $\mathbf{X}_{\mathrm{v}}(\pi(\mathrm{i}), \pi(\mathrm{C}))=\mathbf{X}_{\mathrm{v}^{\circ} \pi}(\mathrm{i}, \mathrm{C}) \quad \forall \mathrm{i} \in \mathrm{N}$, $\forall \mathrm{C} \in 2^{\mathrm{N}}$. This limit exists and it is unique, according to the results explained in section 3 . $\square$

Corollary 2 The crisp solution equivalent to the FNSKE and CNSKE satisfies Efficiency and Symmetry.

Proof It is a particular case of theorem 2.

Theorem 3 The crisp solution equivalent to the FNSKE and CNSKE, satisfy Dummy Axiom.

Proof if $\mathrm{NP}=\left\{\mathrm{i}_{1}, \mathrm{i}_{2}, \ldots, \mathrm{i}_{\mathrm{k}}\right\} \subset \mathrm{N}$ is the set of null players, that is, the set such that $\mathrm{v}(\mathrm{S})=\mathrm{v}\left(\mathrm{S} \cup\left\{\mathrm{i}_{\mathrm{m}}\right\}\right) \forall \mathrm{S} \subset \mathrm{N} \backslash\left\{\mathrm{i}_{\mathrm{m}}\right\}$, where $i_{m} \in N P$, then $v(N)=v(N \backslash N P)$, because of the null player definition. According to definition 3, NINP or one of its subset is the coalition crisp solution equivalent to the FNSKE and CNSKE, because the number of players is a minimum. Taking into account the definitions (1) and (11), the GDI values of the members of NP are null in a subcoalition of NINP.

Remarkl Shapley value is the unique solution which satisfies Efficiency, Symmetry, Dummy Axiom and Additivity, see [14]. The crisp solutions equivalent to the FNSKE and CNSKE satisfy the first three axioms and the example 1 shows that they aren't equal to the Shapley value. Thus, these fuzzy models don't satisfy the Additivity Axiom.

Theorem 4 Every vector of the FNSKE and CNSKE are non-negative, including the members of the crisp solutions equivalent to the FNSKE and CNSKE.

Proof According to theorem (1), the GDI of the FNSKE and the CNSKE are individually rationals. Hence, $\mathbf{X}(\mathrm{i}, \mathrm{C}) \geq \mathrm{v}(\{\mathrm{i}\}) \geq 0$. Hence, evidently the crisp solutions equivalent to the FNSKE and CNSKE satisfy the property. $\square$

Theorem 5 Let $(\mathrm{N}, \mathrm{v})$ and $(\mathrm{N}, \mathrm{w})$ be two cooperative $\mathrm{n}$ person games, such that $\mathrm{w}(\mathrm{C})=\alpha \mathrm{v}(\mathrm{C}) \forall \mathrm{C} \subseteq \mathrm{N}$ and $\alpha \in$ $\Re_{+}{ }^{*}$. Then, $\mathbf{X}_{\mathrm{w}}(\mathrm{i}, \mathrm{C})=\alpha \mathbf{X}_{\mathrm{v}}(\mathrm{i}, \mathrm{C})$ for all coalition $\mathrm{C}$ and player $\mathrm{i} \in \mathrm{C}$, for the FNSKE and the CNSKE.

Proof The formula of the GDI for the second game is:

$$
\begin{aligned}
& \mathbf{X}_{w}(i, C)=w(\{i\})+\frac{r_{w}{ }^{s}(i, C)}{\sum_{j \in C} r_{w}{ }^{s}(j, C)}\left[w(C)-\sum_{j \in C} w(\{j\})\right]= \\
& =\alpha v(\{i\})+\frac{r_{w}{ }^{s}(i, C)}{\sum_{j \in C} r_{w}{ }^{s}(j, C)}[\alpha v(C)- \\
& \left.\sum_{j \in C} \alpha v(\{j\})\right]= \\
& =\alpha\left(v \left(\{i\}+\frac{r_{w}{ }^{s}(i, C)}{\sum_{j \in C} r_{w}{ }^{s}(j, C)} .\right.\right.
\end{aligned}
$$

.$\left.\left[\mathrm{v}(\mathrm{C})-\sum_{\mathrm{j} \in \mathrm{C}} \mathrm{v}(\{\mathrm{j}\})\right]\right)$

Now, let us calculate the first iteration of the algorithm. If the initial value for $w$ is:

$$
\begin{gathered}
\mathbf{X}_{w}^{0}(i, C)=\left\{\begin{array}{l}
w(\{i\})+\eta_{i, C}\left[w(C)-\sum_{j \in C} w(\{j\})\right] \text { if } i \in C, \\
0 \quad \text { if } i \notin C
\end{array}\right. \\
=\left\{\begin{array}{l}
\alpha v(\{i\})+\eta_{i, C}\left[\alpha v(C)-\sum_{j \in C} \alpha v(\{j\})\right] \text { if } i \in C,=\alpha \mathbf{X}_{v}^{0}(i, C), \\
0 \quad \text { if } i \notin C
\end{array}\right.
\end{gathered}
$$

where $\eta_{i, C}$ are random values.

Taking into account that the formula of bargaining capacity (2) depends on formulas based on fuzzy order (3), and this fuzzy order is scale-invariant - in (3), for w, the numerator and denominator are multiplied by the same factor- then, applying the formulas of the algorithm, we obtain $\mathbf{X}_{\mathrm{w}}^{1}(\mathrm{i}, \mathrm{C})=\alpha \mathbf{X}_{\mathrm{v}}^{1}(\mathrm{i}, \mathrm{C})$. Hence, the first value of bargaining capacity satisfies $r_{w}^{s}(i, C)=r_{v}^{s}(i, C) \forall i \forall C$. If we repeat the same idea, we will verify that the last equality is always true.

Therefore, $X_{w}(i, C)=\alpha\left(v(\{i\})+\frac{r_{w}{ }^{s}(i, C)}{\sum_{j \in C} r_{w}{ }^{s}(j, C)}\right.$

$\left.\left[\mathrm{v}(\mathrm{C})-\sum_{\mathrm{j} \in \mathrm{C}} \mathrm{v}(\{\mathrm{j}\})\right]\right)=\alpha \mathbf{X}_{\mathrm{v}}(\mathrm{i}, \mathrm{C})$, if $\mathrm{i} \in \mathrm{C}$.

If $\mathrm{i} \notin \mathrm{C}$ the proportionality is trivial.

Evidently, the crisp solutions equivalent to the FNSKE and the CNSKE satisfy this property. $\square$ 
The theorem shows that proportional games have proportional solutions multiplying by the same factor. This is a particular case of the property covariant, see [13].

Theorem 6 Let $(\mathrm{N}, \mathrm{v})$ be a cooperative n-person game. If two players $i, j \in N$ satisfy the condition $v(S \cup\{i\})=$ $\mathrm{v}(\mathrm{S} \cup\{\mathrm{j}\}) \forall \mathrm{S} \subseteq \mathrm{N} \backslash\{\mathrm{i}, \mathrm{j}\}$, then, $\mathbf{X}(\mathrm{i}, \mathrm{C})=\mathbf{X}(\mathrm{j}, \mathrm{C})$, for the FNSKE and the CNSKE, whenever $i, j \in C$.

Proof In [13] this property is called symmetry. For the sake of clarity, in this paper it is called equality.

Three cases are possible:

- If $\mathrm{i}, \mathrm{j} \notin \mathrm{C}$, then $\mathbf{X}(\mathrm{i}, \mathrm{C})=\mathbf{X}(\mathrm{j}, \mathrm{C})=0$.

- If $i, j \in C$, then $v(C)$ is common for both players.

- If $i \in C$ and $j \notin C$ (or $i \notin C$ and $j \in C$ ) and $C$ is a coalition, where $\mathrm{C}=\mathrm{S} \cup\{\mathrm{i}\}$, then, because of the conditions of the theorem the coalition $\mathrm{C}^{\prime}=$ $\mathrm{S} \cup\{\mathrm{j}\}$ satisfies $\mathrm{v}(\mathrm{C})=\mathrm{v}\left(\mathrm{C}^{\prime}\right)$.

Those cases prove that if $\mathrm{i}$ and $\mathrm{j}$ are permuted, then, the values of the GDI corresponding to these players, for the FNSKE and the CNSKE, will be the same, hence the results of the GDI are the same for both players too.

This proof is valid for the crisp solutions equivalent to the FNSKE and the CNSKE. $\square$

\section{An Illustrative Example}

Example 2 Let $(\{1,2,3,4,5\}, \mathrm{v})$ be a game, where, $\mathrm{v}(\{1,2,4\})=\mathrm{v}(\{1,2,5\})=\mathrm{v}(\{1,2,3,4\})=\mathrm{v}(\{1,2,3,5\})=$ $\mathrm{v}(\{1,2,4,5\})=\mathrm{v}(\{1,2,3,4,5\})=1$, and $\mathrm{v}(\mathrm{S})=0$ otherwise.

\begin{tabular}{|c|c|c|c|}
\hline & $\{1,2,4\}$ & $\{1,2,5\}$ & $\{1,2,3,4\}$ \\
\hline 1 & 0.3340 & 0.3340 & 0.3090 \\
\hline 2 & 0.3340 & 0.3340 & 0.3090 \\
\hline 3 & 0 & 0 & 0.0747 \\
\hline 4 & 0.3320 & 0 & 0.3073 \\
\hline 5 & 0 & 0.3320 & 0 \\
\hline
\end{tabular}

Table 7. The most important values of GDI in the example, for the FNSKE

\begin{tabular}{|c|c|c|c|}
\hline & $\{1,2,3,5\}$ & $\{1,2,4,5\}$ & $\{1,2,3,4,5\}$ \\
\hline 1 & 0.3090 & 0.3891 & 0.3538 \\
\hline 2 & 0.3090 & 0.3891 & 0.3538 \\
\hline 3 & 0.0747 & 0 & 0.0880 \\
\hline 4 & 0 & 0.1109 & 0.1022 \\
\hline 5 & 0.3073 & 0.1109 & 0.1022 \\
\hline
\end{tabular}

Table 8. The most important values of GDI in the example, for the FNSKE

\begin{tabular}{|l|l|l|}
\hline$\{1,2,4\}$ & $\{1,2,5\}$ & $\{1,2,3,4\}$ \\
\hline 0.2662 & 0.2662 & 0.0675 \\
\hline
\end{tabular}

Table 9. The most important truth-values of $f$ (see formula 5) in example, for the FNSKE

\begin{tabular}{|l|l|l|}
\hline$\{1,2,3,5\}$ & $\{1,2,4,5\}$ & $\{1,2,3,4,5\}$ \\
\hline 0.0675 & 0.0342 & 0.0087 \\
\hline
\end{tabular}

Table 10. The most important truth-values of $\mathrm{f}$ (see formula 5) in example, for the FNSKE

\begin{tabular}{|c|c|c|c|}
\hline & $\{1,2,4\}$ & $\{1,2,5\}$ & $\{1,2,3,4\}$ \\
\hline 1 & 0.3339 & 0.3339 & 0.3089 \\
\hline 2 & 0.3339 & 0.3339 & 0.3089 \\
\hline 3 & 0 & 0 & 0.0750 \\
\hline 4 & 0.3322 & 0 & 0.3072 \\
\hline 5 & 0 & 0.3322 & 0 \\
\hline
\end{tabular}

Table 11. The most important values of GDI in the example, for the CNSKE

\begin{tabular}{|l|l|l|l|}
\hline & $\{1,2,3,5\}$ & $\{1,2,4,5\}$ & $\{1,2,3,4,5\}$ \\
\hline 1 & 0.3089 & 0.4006 & 0.3645 \\
\hline 2 & 0.3089 & 0.4006 & 0.3645 \\
\hline 3 & 0.0750 & 0 & 0.0889 \\
\hline 4 & 0 & 0.0994 & 0.0910 \\
\hline 5 & 0.3072 & 0.0994 & 0.0910 \\
\hline
\end{tabular}

Table 12. The most important values of GDI in the example, for the CNSKE

\begin{tabular}{|c|c|c|}
\hline$\{1,2,4\}$ & $\{1,2,5\}$ & $\{1,2,3,4\}$ \\
\hline 0.736 & 0.736 & 0.5975 \\
\hline
\end{tabular}

Table 13. The most important truth-values of $f$ (see formula 10) in example, for the CNSKE

\begin{tabular}{|r|r|c|}
\hline$\{1,2,3,5\}$ & $\{1,2,4,5\}$ & $\{1,2,3,4,5\}$ \\
\hline 0.5975 & 0.5725 & 0.4494 \\
\hline
\end{tabular}

Table 14. The most important truth-values of $f$ (see formula 10) in example, for the CNSKE

These solutions are efficient, the values by columns in tables (7), (8), (11) and (12) sum 1. The values of the solution that don't appear in the tables are all zero. All the GDI values are non-negative.

The crisp solutions equivalent to FNSKE and CNSKE are the sets

$\{(0.334,0.334,0,0.332,0),(0.334,0.334,0,0,0.332)\}$ and $\{(0.3339,0.3339,0,0.3322,0),(0.3339,0.3339,0,0,0.3322)\}$, respectively. They correspond to the coalitions with maximum values of tables (9), (10), (13) and (14) and a minimum number of players, 3 . The player 3 is a null player, in the crisp solution vectors, he or she obtains a gain 0 . Also, the players 1 and 2, the most 'powerful' because they are included in all the coalitions with biggest worth, obtain the biggest gains in the coalitions containing them.

Let $(\{1,2,3,4,5\}, w)$ be a game, where, $w(\{1,2,4\})=$ $\mathrm{w}(\{1,2,5\})=$

$=\mathrm{w}(\{1,2,3,4\})=\mathrm{w}(\{1,2,3,5\})=\mathrm{w}(\{1,2,4,5\})=$ $\mathrm{w}(\{1,2,3,4,5\})=2$, and $\mathrm{w}(\mathrm{S})=0$ otherwise. It satisfies $\mathrm{w}=2 \mathrm{v}$.

The GDI are summarized in tables (15), (16), (17) and (18). The new values are the double of the original values. The 'likelihood to reach an agreement in the coalitions', tables (9), (10), (13) and (14), don't change in the new game. 


\begin{tabular}{|r|c|c|c|}
\hline & $\{1,2,4\}$ & $\{1,2,5\}$ & $\{1,2,3,4\}$ \\
\hline 1 & 0.6680 & 0.6680 & 0.6180 \\
\hline 2 & 0.6680 & 0.6680 & 0.6180 \\
\hline 3 & 0 & 0 & 0.1493 \\
\hline 4 & 0.6640 & 0 & 0.6147 \\
\hline 5 & 0 & 0.6640 & 0 \\
\hline
\end{tabular}

Table 15. The most important values of GDI in the example if the gains are doubled, for the FNSKE

\begin{tabular}{|c|c|c|c|}
\hline & $\{1,2,3,5\}$ & $\{1,2,4,5\}$ & $\{1,2,3,4,5\}$ \\
\hline 1 & 0.6180 & 0.7782 & 0.7076 \\
\hline 2 & 0.6180 & 0.7782 & 0.7076 \\
\hline 3 & 0.1493 & 0 & 0.1760 \\
\hline 4 & 0 & 0.2218 & 0.2044 \\
\hline 5 & 0.6147 & 0.2218 & 0.2044 \\
\hline
\end{tabular}

Table 16. The most important values of GDI in the example if the gains are doubled, for the FNSKE

\begin{tabular}{|c|c|c|c|}
\hline & $\{1,2,4\}$ & $\{1,2,5\}$ & $\{1,2,3,4\}$ \\
\hline 1 & 0.6678 & 0.6678 & 0.6177 \\
\hline 2 & 0.6678 & 0.6678 & 0.6177 \\
\hline 3 & 0 & 0 & 0.1500 \\
\hline 4 & 0.6643 & 0 & 0.6145 \\
\hline 5 & 0 & 0.6643 & 0 \\
\hline
\end{tabular}

Table 17. The most important values of GDI in the example if the gains are doubled, for the CNSKE

\begin{tabular}{|c|c|c|c|}
\hline & $\{1,2,3,5\}$ & $\{1,2,4,5\}$ & $\{1,2,3,4,5\}$ \\
\hline 1 & 0.6177 & 0.8013 & 0.7291 \\
\hline 2 & 0.6177 & 0.8013 & 0.7291 \\
\hline 3 & 0.1500 & 0 & 0.1777 \\
\hline 4 & 0 & 0.1987 & 0.1821 \\
\hline 5 & 0.6145 & 0.1987 & 0.1821 \\
\hline
\end{tabular}

Table 18. The most important values of GDI in the example if the gains are doubled, for the CNSKE

Let us note the validity of theorem (6) in the example. Players 1 and 2, for instance, have equal values in all coalitions; therefore their values are always the same.

The example is a simple game, because the characteristic function has values 0 or 1 . It could be interpreted like a voting problem. It is the application of the solution for a political, non-financial, problem.

\section{Concluding Remarks}

The imputation axioms, the axioms of nonnegativeness, proportionality, equality and the Shapley's axiom set, except Additivity, are considered rational in the classic approach to cooperative n-person games, according to the concept of rationality in Decision Theory, particularly in Normative Decision Theory. The consensus about rationality concerning such axioms can be used to prove the rationality of other solutions to cooperative n-person games.

The FNSKE and CNSKE models based on experts' knowledge on bargaining are recent solutions to coopera- tive n-person games. In this paper, a demonstration has been developed to show that the elements of this solution are imputations. Hence, these elements are group rational and individually rational.

The elements of these solutions satisfy two Shapley's axioms: Efficiency and Symmetry, and also, nonnegativeness, proportionality and equality. The fact that the elements of these solutions do not satisfy Additivity, has been exposed by a counterexample.

A crisp solution to the game equivalent to the FNSKE and the CNSKE is a solution for the coalition with the same value of the grand coalition characteristic function, having the biggest value of likelihood to reach an agreement and the lowest number of players. It has been proved that this crisp solution satisfies the Dummy Axiom of the Shapley's axiom set.

The rationality of the FNSKE and CNSKE can be considered a proof that these new solutions can be used to solve any cooperative n-person game problem, not only financial negotiation problems.

\section{References}

[1] M. Bazerman and M. Neale, Negotiating Rationally. The Free Press, New York, 1992.

[2] B.G. Buchanan and E.H. Shortliffe, Knowledge engineering, In: Buchanan BG, Shortliffe EH (eds) RuleBased Expert Systems -The MYCIN Experiments of the Stanford Heuristic Programming Project. Reading, Addison-Wesley, Massachusetts, 1984, 147-158

[3] R. Espín, Quantitative indices for decision making (in spanish). Ph.D Thesis, Higher Technical Institute José Antonio Echeverría, Havana, Cuba, 2000.

[4] R. Espín, E. Fernández, G. Mazcorro, M.I. Lecich, A fuzzy approach to cooperative n-person games. European Journal of Operational Research 176:17351751, 2007.

[5] R. Espín, E. Fernández and E. González, A logic system for reasoning and decision making: Geometric mean based compensatory logic (in spanish). Investigación Operacional, 32: 230-245, 2011.

[6] R. Fisher and W. Ury Getting to Yes Negotiation Agreement Without Giving. Penguin Books, New York, 1983.

[7] S. French, Decision Theory: An Introduction to the Mathematics of Rationality. Halsted Press, New York-Brisbane-Toronto, 1986.

[8] E. González, R. Espín and G. Mazcorro, Fuzzy negotiation solutions of n-person cooperative games by knowledge engineering in bargaining, Group Decision and Negotiation, 21:133-152, 2012.

[9] M. Mares, Fuzzy Cooperative Games. Cooperation with vague expectations., physica-verlag edn. A Springer - Verlag Company, Heidelberg,New York, 2001.

[10] M. Maschler, The Worth of a Cooperative Enterprise to Each Member. In: Wooders MH (ed) Topics in Mathematical Economics and Game Theory. Essays 
in Honor of Robert J. Aumann, American Mathematical Society, 1999.

[11]H. Raiffa, The Art and Science of Negotiation. Harvard University Press, London, 1982.

[12]L. Thomas, Games, Theory and Applications. John Wiley, New York, 1984.

[13] R. Van-Den-Brink and Y. Funaki, Axiomatizations of a class of equal surplus sharing solutions for tugames. Theory and Decision 67:303-340, 2009.

[14]E. Winter, The shapley value. In: Aumann RJ, Hart $\mathrm{S}$ (eds) Handbook of Game Theory, Elsevier B.V., 2025-2054, 2002.

[15]L. Zadeh, Fuzzy Sets. Information and Control 8:338-353, 1965.

[16] L. Zadeh, The concept of a Linguistic Variable and its Application to Approximate Reasoning-II. Information Sciences 8:301-357, 1975. 